\title{
Brief history of X-ray tube patents
}

\author{
Marcio Luis Ferreira Nascimento \\ PROTEC/PEI - Postgraduate Program in Industrial Engineering, Department of Chemical Engineering, Polytechnic School, Federal University of Bahia,
} Rua Aristides Novis 2, Federação, 40210-630 Salvador, Bahia, Brazil

Keywords:

X-ray

Patent

History

Technology

\begin{abstract}
A B S T R A C T
An X-ray tube is essentially a vacuum glass tube that produces X-rays from cathode rays striking a metal target. They were discovered by Wilhelm Conrad Röntgen in Würzburg, Germany, on November 8, 1895, who published on December 28, 1895. This discovery played a role in the beginning of revolutionary changes in the understanding of the physical world. The first patent was published on March 21, 1896, in record time by Siemens \& Halske (S\&H) Company. Soon other patents for new advances were claimed. A remarkable development was proposed by William David Coolidge's patent in 1913 with General Electric (GE). Surprisingly, Röntgen did not apply for patents for the inventions based on his discoveries, and donated the money from his Nobel Prize to the University of Würzburg. This paper presents a brief history about this amazing discovery and its notable related patents. More than 19,000 patents were filed around the world until 2013 according to searches made on the European Patent Office databases. For the same period there were published 277 patents naming Röntgen in the title or abstract, and 648 using Roentgen. Up to the so-called golden era (1950s) most of the patents were from companies such as Philips, GE and Westinghouse, by a range of different inventors.
\end{abstract}

(C) 2014 Elsevier Ltd. All rights reserved.

\section{Introduction}

From as early as 1879 , many scientists were interested in the newly discovered radiant matter described as cathode rays - a stream of electrons emitted from an electrode as demonstrated by Sir William Crookes. In the winter of 1895 Wilhelm Conrad Röntgen (Fig. 1a) investigated the external effects from the newly developed types of vacuum tube equipment. Precisely why Röntgen began these experiments is not known, possibly just scientific curiosity. Purposefully, he bought the appropriate equipment for investigating electrical high-voltage discharges in such glass tubes. In his lab he unexpectedly noticed a barium platinocyanide screen fluorescing as he generated cathode rays in a Crookes tube $6 \mathrm{ft}$ away [1]. This undoubtedly created a field of interest for the experimenters of the time. It is important to note that Joseph J. Thomson was to announce that cathode rays were made of particles called electrons only one year later and received a Nobel Prize in Physics in 1906 for his discovery [2]. Thus Röntgen speculated that a new kind of rays

\footnotetext{
* Vitreous Materials Lab, Institute of Humanities, Arts and Sciences, Federal University of Bahia, Rua Barão de Jeremoabo s/n, Idioms Center Pavilion (PAF IV), Ondina University Campus, 40170-115 Salvador, Bahia, Brazil.

E-mail address: mlfn@ufba.br.

URL: http://www.protec.ufba.br, http://www.lamav.ufba.br
}

might be responsible for such effect; the new rays were temporarily termed $X$-rays, the $X$ standing for 'unknown' [3].

Soon Röntgen was appointed as Director of Würzburg Institute of Physics, and later as Rector. However leaving aside for a time his duties to the university and to his students, he spent the next six weeks in his laboratory, began a number of very systematic experiments working alone and sharing nothing with his colleagues. For example, he noticed that the X-rays were not deflected by magnetic fields, and they penetrated many kinds of matter. He also encased the glass tube in black cardboard. To his surprise, a fluorescent screen lit up. While experimenting with the screen, his hand came between the tube and the fluoroscopic screen, he saw the bones of his own hand, and wrote about it.

Almost two weeks after his discovery, he took the very first Xray picture of his wife Anna Bertha's hand (Fig. 1b). The Würzburg Physico-Medical Society was the first to hear of the new rays that could penetrate the body and photograph its bones. Röntgen wrote the paper Über eine neue Art von Strahlen (On new kind of rays) [4], in which he presented a qualitative description and production of the new radiation (Fig. 1c). Almost buried among other explanations in this paper were the words 'Hält man die Hand zwischen den Entladungsapparat und den Schirm, so sieht man die dunkleren Schatten der Handknochen in dem nur wenig dunklen Schattenbild der Hand' (If one places one's hand between the discharge tube and the 
(a)

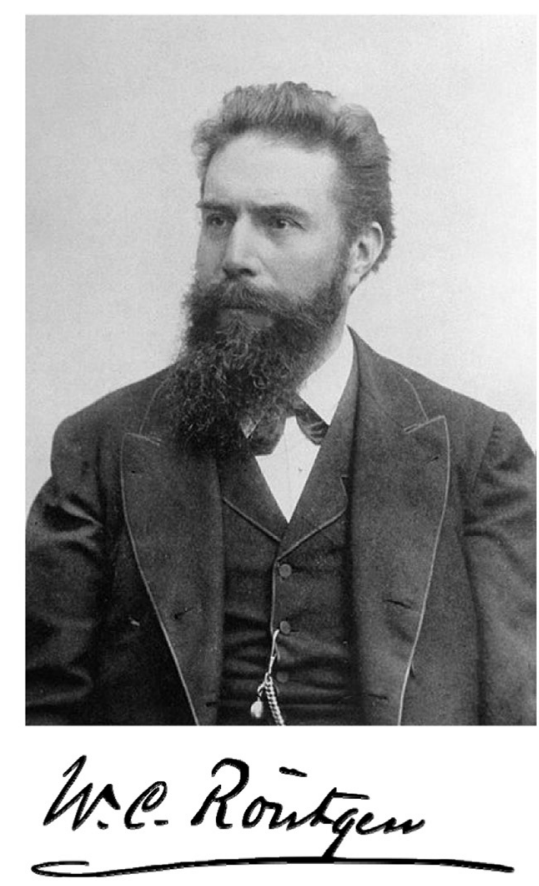

(b)

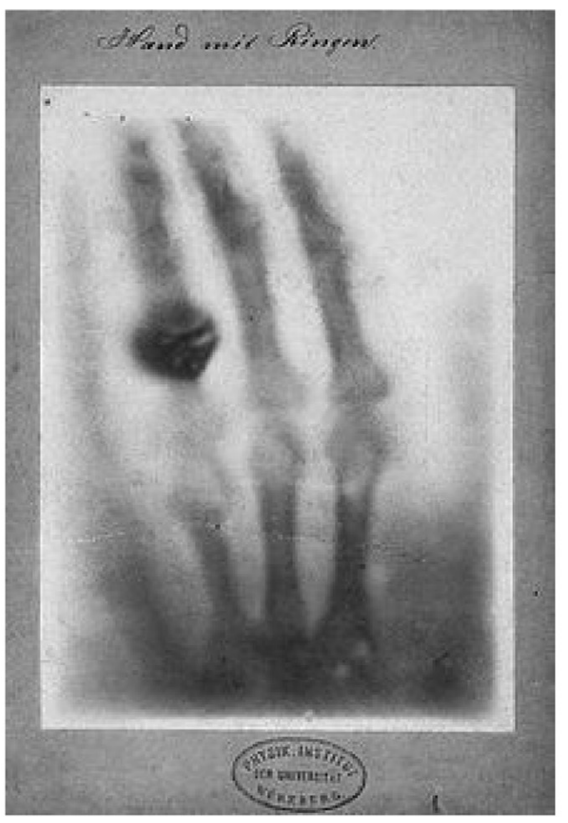

(c)

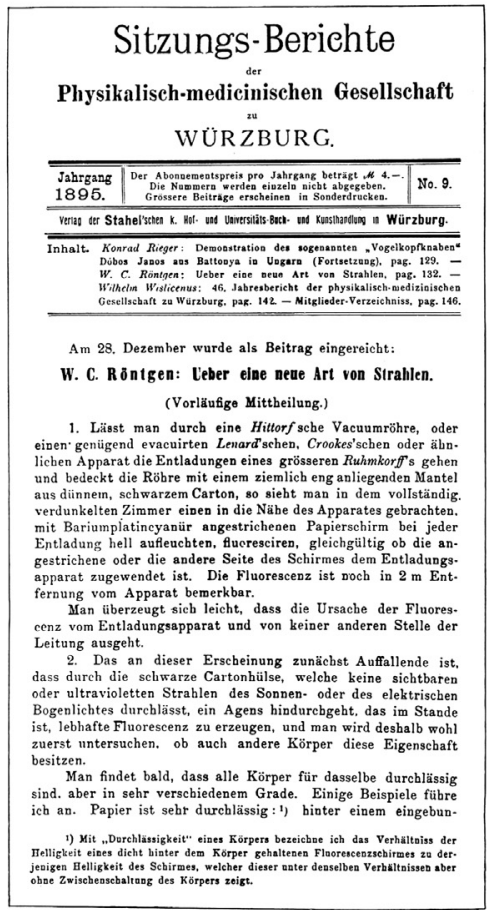

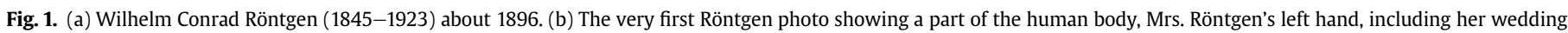
ring (there is also another ring). (c) The first page of X-ray paper of 1895 (http://www.roentgenmuseum.de/).

screen, one can see the dark shadows of the bones against the lighter shadows of the hand). This single description of an experiment with a hand would later have an incredible influence on the development of the new rays for medical applications. A few years later in 1901 he received the first Nobel Prize in Physics (http:// www.nobelprize.org/). The award was officially 'in recognition of the extraordinary services he has rendered by the discovery of the remarkable rays subsequently named after him'.

Word of this newly discovered X-rays traveled quickly throughout the scientific world and through the popular press, and a flurry of experiments at a multitude of scientific institutions commenced. The name X-ray stuck, though over Röntgen's great objections, many of his colleagues suggested calling them Röntgen rays. They are still referred to as such in many languages, including German, Finnish, Russian, Japanese, Dutch and Norwegian. The fact was that many people immediately recognized the potential medical implications of such a technology [5]. The earliest and most obvious clinical application of X-rays was for detection and characterization of fractures and dislocations.

\section{First news on $X$-ray discovery}

On Sunday, 5 January 1896 the German newspaper Die Presse carried the news of Röntgen's discovery on its front page. The news of the new rays was declared in The Daily Chronicle of 6, January 1896. Shortly after, a brilliant electrical engineer, Alan A. Campbell Swinton did the same experiments in England with an X-ray tube made by Alfred C. Cossor, a famous producer of high quality Crookes tubes, after the description of Röntgen from his papers. It was a small pear shaped tube with two electrodes one in the form of a ring which can be seen against the wall on a photographic picture from The Windsor Magazine, spring edition 1896. He is credited with being the first in the United Kingdom to make a radiograph of human anatomy when he radiographed his own hand on 13, January 1896 [6].

In the US the first X-ray analysis were made by brothers Edwin and Gilman Frost. Dr. Gilman Frost was a professor at the Dartmouth Medical School and had just received a patient with a possible broken bone. The patient was 14-year-old Eddie McCarthy, a local schoolboy, who had been ice-skating on the Connecticut River when he fell headfirst onto the ice. He reached out to halt his fall, but fell with such force that he severely injured his wrist. Dr. G. Frost told his patient about the experiments with X-rays and what the technology could do for his case, and he consented to have his arm X-rayed using a Pulyui lamp (a popular type of X-ray tube developed by the Ukrainian born physicist Ivan Pulyui). On February 3, 1896, Dr. G. Frost sat the patient down and placed his arm under the tube. After an exposure time of 20 min the first clinical X-ray photograph in America was taken. Subsequently the brother Dr. E. Frost submitted an article, dated February 14, 1896, about his experiments with X-rays to the magazine Science [7].

In the meantime, on 16 January, 1896 The New York Times announced the discovery as a new form of photography, which revealed hidden solids, penetrated wood, paper, and flesh, and exposed the bones of the human frame - 'Men of science in this city are awaiting with the utmost impatience the arrival of English technical journals which will give them the full particulars of Professor Röntgen's discovery of a method of photographing opaque bodies'. The paper concluded by predicting the 'transformation of modern surgery by enabling the surgeon to detect the presence of foreign bodies'. On the same day Nature included a 17 line description of Röntgen's discovery [8], as a follow-up to a published accurate translation of Röntgen's paper on 23 January, with comments by A. A. Campbell Swinton [9] which included an excellent photograph of a living human hand. According to Otto Glasser not less than 1044 books and pamphlets on Röntgen's rays were published throughout the 
world just in 1896 [10]. It is difficult to think of any event of scientific discovery that spread throughout the scientific world of the late 19th century with such speed.

\section{Brief technology description}

X-rays are waves of electromagnetic energy. They behave in much the same way as light rays, but at much shorter wavelengths - in the range of $0.01-10 \mathrm{~nm}$ - and are thus capable of penetrating some thickness of matter. As with any electronic vacuum tube, there is a cathode, which emits electrons into the vacuum and an anode to collect the electrons, thus establishing a flow of electrical current, known as the beam, through the tube. A high-voltage power source, for example $30-150 \mathrm{kV}$, is connected across cathode and anode to accelerate the electrons. The X-ray spectrum depends on the anode material and the accelerating voltage. In many applications, the current flow is typically in the range $1 \mathrm{~mA}$ to $1 \mathrm{~A}$.

The first generation of 'Crookes type tubes' were used until the 1920 s. Until the late 1980 s, X-rays were generated merely by utilizing high-voltage, AC to DC variable power supplies. After that a different method of control emerged, called high speed switching. This followed the electronics technology of switching power supplies, and allowed for more accurate control of the X-ray unit, higher quality results, and reduced X-ray exposures. Electrons from the cathode collide with the anode material, usually tungsten, molybdenum or copper, and accelerate other electrons, ions and nuclei within the anode material.

The range of photonic energies emitted by the system can be adjusted by changing the applied voltage, and installing aluminum filters of varying thicknesses. These aluminum filters are placed in the path of the X-ray beam to remove 'soft' or non-penetrating radiation of up to energy of about $10 \mathrm{keV}$. The number or dose of emitted X-ray photons is adjusted by controlling the current flow and exposure time. After considerable use, the tube becomes unstable even at lower voltages, and must be replaced. So the tube assembly or tube head is removed from the X-ray system, and replaced with a new tube assembly.

Interestingly, Abreugraphy (also called mass miniature radiography or chest photofluorography) a technique for mass screening for tuberculosis using a miniature (50-100 mm) photograph of the thorax imaged on the screen of an X-ray fluoroscope, was first developed in 1935 by Manuel Dias de Abreu, a Brazilian physician and pulmonologist.

\section{Patents \& discussion}

The first patent for an X-ray tube was prepared by Siemens $\mathcal{E}$ Halske (S\&H), based on Crookes tube. On March 24, 1896, a mere three months after the discovery of X-rays, S\&H received a Deutsches Reichs Patent "Eine neue Röntgenlampe mit regulierbarem Vakuum" for 'a new X-ray lamp with regulated vacuum', patent number DE91028 (Fig. 2a). The innovation considered that 'for the first time it was possible to manually regulate gas pressure in the X-ray tube so that tube wear was reduced and the pressure could be adjusted to ensure the most intensive radiation and the sharpest images'. The potential use of the newly patented object was also clearly defined as 'Due to the intensity of its radiation,... X-ray lamp is particularly suited for the radioscopic screening of complete adult bodies.'

According to the Siemens Company 'this innovation was preceded by intensive research work in the Siemens labs in Berlin, where employees had immediately begun reproducing Röntgen's experiments after the announcement of the discovery in January 1896. Since (a)

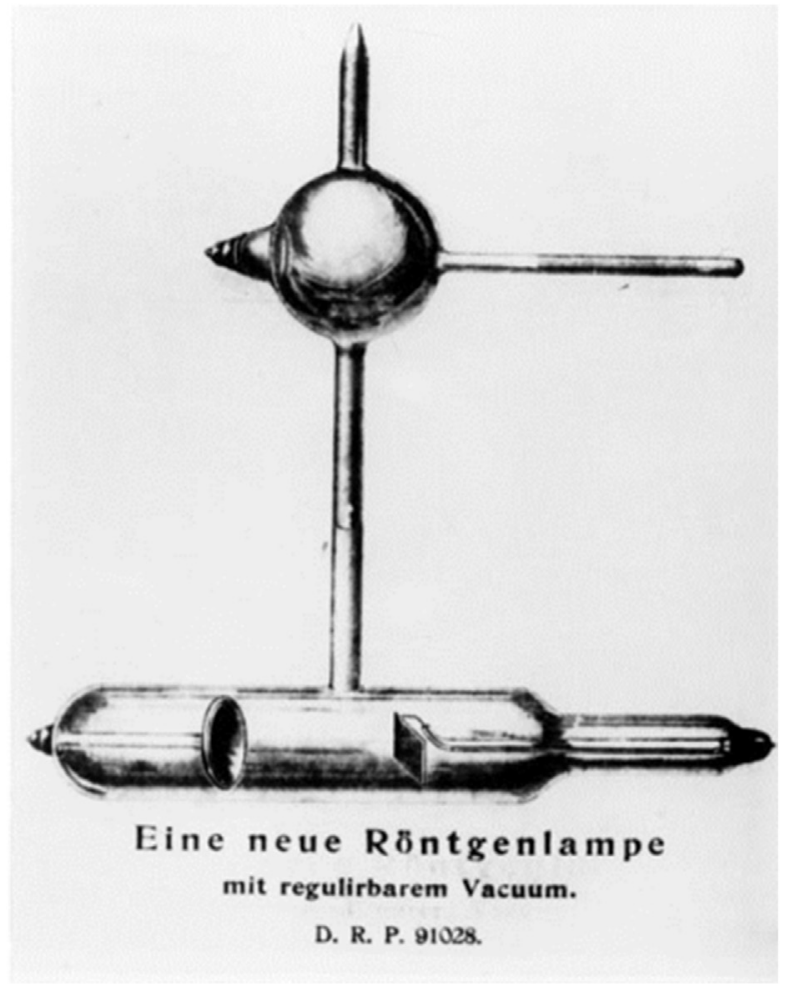

(b)

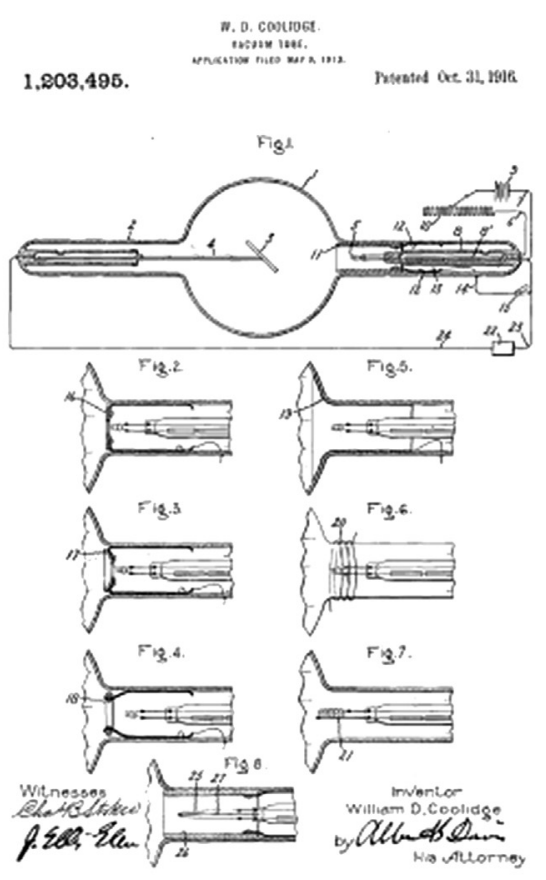

Fig. 2. (a) Illustration of Siemens \& Halske X-ray patent no. DE91028 (1897) [11]. (b) Drawing from Coolidge X-ray tube patent no. US 1,203,495 (1913). 
Röntgen himself refused to take out patents on his own discovery, anyone could work with the new kind of rays or exploit them commercially' thus focusing on 'perfecting the process and adapting it to practical needs' [11]. In the U.S.A., Thomas Edison used modified incandescent light bulbs to produce the new rays. He boasted to reporters that anyone could make photographs of skeleton hands; that was 'mere child's play' [1]. Edison dropped X-ray research around 1903.

Other important improvements based on Crookes tube were done thereafter. For example, to meet the demand for higher radiation intensity, the idea of cooling the anti-cathode with water produced a new patent in 1899 for Carl H. F. Müller, and the product named as Müller-Rapidröhre. Only two years later in 1901, the British Röntgen Society (founded June, 3rd 1897) awarded the Müller tube their gold medal for the best X-ray tube out of 28 tubes tested [12].

The early X-ray tubes were all ion tubes. A major problem with these tubes was that the intensity (controlled by current) and penetration (controlled by applied voltage) of these tubes could not be independently controlled [12]. The current in the tube, which resulted from the voltage generating the gas discharge, was very dependent on the gas pressure. However, this gas pressure decreased over time because the glass wall absorbed the gas ions released by the discharge. Thus an increasingly higher voltage was needed to initiate the discharge, resulting in a hardening of the radiation.

The Crookes X-ray tube was improved by William David Coolidge who filed for a patent in 1913 and finally was granted as US patent no. 1,203,495 in 1916. Coolidge was an electrical engineer from Massachusetts Institute of Technology (MIT), who received his doctorate from the University of Leipzig in Germany. He was the director of the GE Research Laboratory in 1932 and later in 1940 vice-president of the corporation. The Coolidge tube, also called hot cathode tube, differs radically from Crookes tube, and is the most widely used until today. It works with a very good quality vacuum (about $10^{-4} \mathrm{~Pa}$, or $10^{-6} \mathrm{Torr}$ ). In the Coolidge tube, the electrons are produced by thermionic effect from a tungsten filament heated by an electric current - this in fact was a real innovation because the filament is the cathode of the tube. A high voltage potential exists between the cathode and the anode, the electrons are thus accelerated, and then hit the anode, thus producing the X-rays. This made it possible to control the voltage and the tube current independently by varying the current through the filament of the cathode. The power of a Coolidge tube usually ranges from 0.1 to $18 \mathrm{~kW}$. His goal was to achieve radiation output of the tube about 10 times higher than previous technology. In his US patent no. 1,203,495 Coolidge claimed a 'new variety of tube, differing both in its principles ... and operating characteristics'. Another innovation is related to the variability in the location of the focal spot, promoting the penetrability, or in other words, a better adjustment of 'hard' and 'soft' X-rays. He also claimed that his new dispositive presented practically no fluorescence of the glass, negligible production of secondary Xrays from glass and better steady focusing, constant voltage as well as sharpness definition of the X-ray photographs. Other alternative tube forms were proposed, mainly because he noted that special relations of the elements of the tube affect its characteristics.

Further work of Coolidge was published in US patent no. $1,215,116$ in 1917. Diverting from his previous patent, that dealt with only the X-ray tube, this patent dealt with the overall apparatus. Basically speaking, the apparatus comprises an X-ray device operable to yield a great output of X-rays without overheating and melting the metal on the surface of electrode subjected to the discharge. Hence his invention proposed 'an X-ray tube of increased capacity provided by rotating the tube as a whole and deflecting the cathode beam out of line with the axis of rotation, thus renewing the surface subjected to the discharge while keeping the focal sport fixed'.

With new developments, there emerged new problems to solve. Two such problems with early X-ray devices were the emission of undesired radiation in all directions and the hazard of exposed high voltage cables. However, it is important to note that there have been only scattered references in the literature about the early workers who dedicated their life, and death, to X-rays, as pointed by Sansare et al. [13] in a historical perspective. Radiology has come of age since then, due to absorbed dose control through trial and error. For example, large exposure times have been reduced from hours to milliseconds and there has been a change from analog to digital control.

Technological solutions and many patents were published on focusing or even shielding high tension cables. A new enhancement of X-ray technique was the rotating anode tube (e.g. patent GB 339,715 published 1930 ), where the anode could then be rotated by electromagnetic induction from a series of stator windings outside the evacuated tube, to avoid the overheating of a fixed point on the anode surface. This apparatus called the Rotalix Metalix tube was introduced by Philips in 1929. However, the demand for increased output from the X-ray tube continued unabated in the following years. Among many companies, Philips, for instance, introduced the Maximus Rotalix Ceramic X-ray tube in 1989 [14]. This had a new rotating anode, which was the first tube that replaced the existing ball bearings with spiral groove bearings and a liquid-metal alloy as a lubricant. This design reduced the noise produced by the tube, increased the lifetime and heat dissipation, and improved current conduction.

A search on European Patent Office (Espacenet at http://www. epo.org/) with the key words ' $X$ ray tube' (Fig. 3a), and 'Röntgen' (Fig. 3b) gave the patents published results per year on a worldwide base. From this figure is possible to note an exponential increase in patents since the first claim in 1896 . Looking only for titles using ' $\mathrm{X}$ ray tube', it was possible to find 5580 patents filed. If considering title or abstract, the number reached 19,297 patents up to 2013 and is still increasing. The author did not consider searches using 'cathode ray' because much of such works are related to communication, mainly television. As a curiosity, for the same period 277 patents were published with 'Röntgen' in title or abstract, mainly by German companies, but its use started to diminish from Second World War onwards. Interestingly, using the English language equivalent search term 'Roentgen' in title or abstract for the same period, 648 published patents were returned. So 'Roentgen' is used more often in English language text as the character 'ö' is not commonly used.

From Fig. 3b is also possible to note that up to 1933 the term Röntgen characterized such patent tube, and was surpassed by the usual name "X ray" (used on title only) from that time. However, since 1903 the term "X ray" was intensively used in abstracts, more than Röntgen rays. It seems that there was no influence on the number of patent publications during the first or second World Wars, or even after the 1929 Wall Street Crash.

Considering the so-called 'golden era', up the 1950s, it is possible to note that X-ray patent inventions were done by different researchers, including Albert Bouwers et al. (e.g. patent US 2,054,493, 1936 representing Philips Co.); Montford Morrison et al. (e.g. patent CA 353,076, 1935 representing Westinghouse Co.); Zed Atlee et al. (e.g. patent CA 390,809, 1940 representing GE Canada); William Coolidge et al. (most of time representing $\mathrm{GE}$ ). Analyzing results from term "X ray tube" only in abstract in such a period, there were $68.2 \%$ patents from US, $24.8 \%$ from Canada, 6.0\% from Great Britain and only 0.9\% from German inventors. 


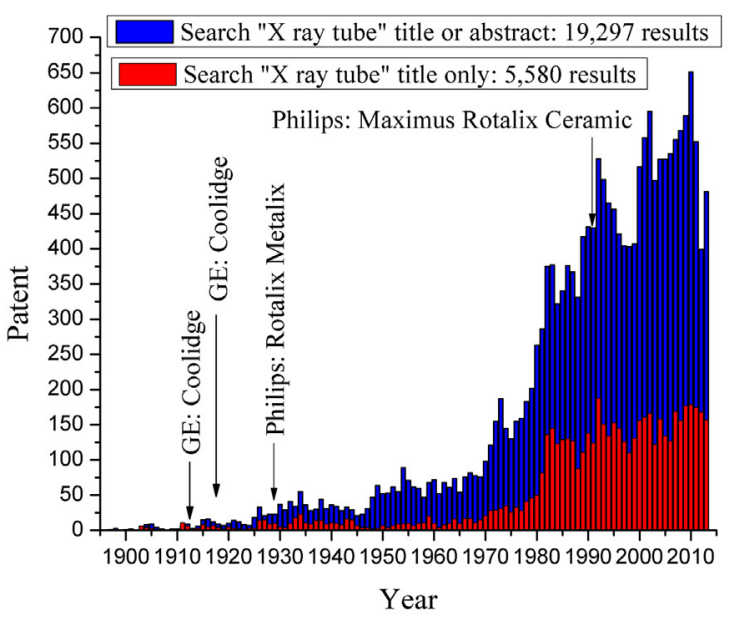

(a)

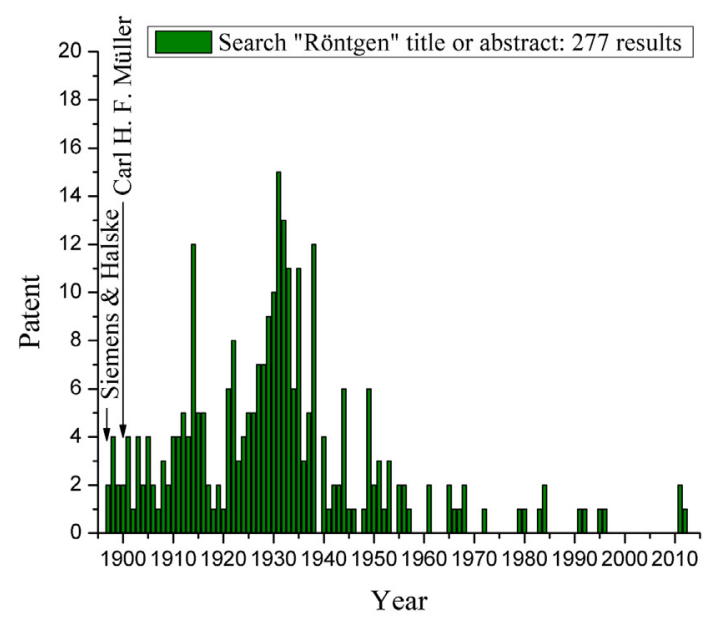

(b)

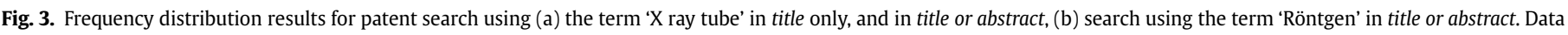
from http://www.epo.org/. Some significant patent improvements are indicated by arrows.

\section{Perspectives}

For a long time, the X-ray imaging system was a highly technical device that was made up of separate components. Today, these are well-designed systems utilizing the newest technologies, largely automated functionality, and very intuitive and user-friendly controls. For example, increasing demand for high-performance Computed Tomography (CT) scanning and angiography systems has driven development of very high performance medical X-ray tubes. Briefly speaking, CT is a medical imaging procedure that utilizes computer-processed X-rays to produce tomographic images or 'slices' of specific areas of the body (US patent no. 3,922,552, 1975). However, a radiograph (X-ray image) and a CT-scan show different types of information. An X-ray image is a simple 2D picture and a CT-scan is 3D. By imaging and looking at several 3D slices of a body is possible not only know if a tumor is present, but roughly how deep it is in the body.

Thus, requirements for X-ray sources are still growing, specially in non-destructive testing applications. According to Schulz [15], the main features and respective benefits are: $i$ ) increased power with higher through put plus better contrast resolution; ii) Smaller focal spot with higher special resolution plus higher detectability; iii) Smaller size and lower weight with less space occupation plus easy to handle; iv) High energy with higher penetration. For example, contemporary $\mathrm{CT}$ tubes have power ratings of up to $100 \mathrm{~kW}$ and anode heat capacity of $6 \mathrm{MJ}$, yet retain an effective focal spot area of less than $1 \mathrm{~mm}^{2}$. Some X-ray examinations need very high-resolution images and do therefore require microfocus X-ray tubes that can generate very small focal spot sizes, typically below $50 \mu \mathrm{m}$ in diameter. In fact, according to Gaertner [14], X-ray tubes have not experienced any recent decline and continue to grow with respect to total sales worldwide (in billions of US\$, just considering data from 1970 up to 2010). The current development efforts worldwide are aimed mainly at better electron-beam focus control and improved cathodes. Currently, there are no real alternatives to $\mathrm{X}$-ray tubes with the exception of micro-pinch discharges for soft Xrays and portable miniature X-ray sources [14].

\section{Conclusion and final comments}

The first application of X-ray techniques was made in Germany by Wilhelm Conrad Röntgen in November 1895 . Nowadays, X-rays are still the most frequently applied technology for medical imaging. From this first use, different groups became interested in creating and improving the technical devices. It is still difficult to think of any other scientific discovery that spread so fast throughout world and that was not claimed in a patent by its first inventor/researcher. In fact, Coolidge's invention revolutionized the generation of X-rays and is the model upon which all X-ray tubes are still based, including health applications. As we have seen, a great deal has changed over the years - in technology as well as in applications. A lot of improvements for X-ray tubes have been introduced in the past by Siemens, Westinghouse, Toshiba, General Electric, Philips, Shimadzu, HP, Institutes/Universities, independent researchers, among others, with interesting future perspectives. The development of modern science would clearly have been difficult without the benefits of Röntgen rays and subsequent technological improvements. Companies and institutions around the world are still investing in new technologies and process components, developing even more new X-ray tube patents.

\section{Editor's note}

The following publications may also be of interest to readers of this article:

- Carlson W. Innovation in medical technology: Elihu Thomson, General Electric, and X rays in 1896. Medical Instrumentation, 1982, 16(4), 218

- Ramsey L. British X-ray patents, 1896-1900. Radiography, 1969, 35(420), 285-291.

\section{Acknowledgments}

The author thanks Brazilian CNPq agency contracts 305373/ 2009-9, 479799/2010-5, 300938/2012-8 and 471546/2012-7 for financial support. Special thanks to the editor and 'blind' reviewers who gave so freely of their time and talents and suggested very nice improvements to this manuscript.

\section{References}

[1] Assmus A. Early history of X rays. Beam Line 1995;25:10-24.

[2] Spear B. J. J. Thomson, the electron and the birth of electronics. World Pat Inf 2006;28:330-5.

[3] Martins RA. A Descoberta dos Raios X: Primeiro Comunicado de Röntgen. Rev Bras Ens Fis 1998;20:373-90 [In Portuguese]. 
[4] Röntgen WC. Über eine neue Art von Strahlen. Sitzungsberichte der Wuerz burger Physik.-medic. Gesellschaft, Wuerzburg 1895:9:132-41 [in German].

[5] Posner E. Reception of Röntgen's discovery in Britain and U.S.A. Br Med 1970;4:357-60

[6] Mould RF. The early history of X-ray diagnosis with emphasis on the contributions of physics 1895-1915. Phys Med Biol 1995;40:1741-87.

[7] Frost EB. Experiments on the X-rays. Science 1896;3:235-6.

[8] Anonymous. Notes. Nature 1896;53:253.

[9] Swinton AAC. Professor Röntgen's discovery. Nature 1896;53:276-7.

[10] Glasser O. Wilhelm Conrad Röntgen and the early history of the Röntgen rays. London: John Bale, Sons and Danielson; 1933.

[11] Prellwitz F. Zur Geschichte der medizinischen Röntgenröhren, Erlangen; 1979 [in German].

[12] Hofman JAM. The art of medical imaging: Philips and the evolution of medical X-ray technology. Medica Mundi 2010;54:5-21.

[13] Sansare K, Khanna V, Karjodkar F. Early victims of X-rays: a tribute and current perception. Dentomaxillofac Radiol 2011;40:123-5.
[14] Gaertner G. Historical development and future trends of vacuum electronics. Vac Sci Technol B 2012;30:060801.

[15] Schulz J. Innovation in X-ray technology. Rev Mater 2011;16(4):867-76.

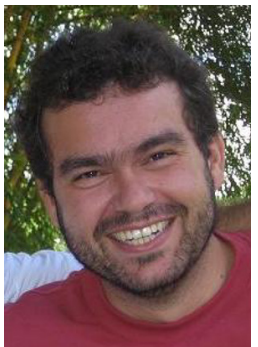

Marcio L.F. Nascimento is a physicist from the University of São Paulo, Brazil, with an MSc and PhD in Condensed Matter Physics from Universities of São Paulo and Federal University of São Carlos, respectively. He is presently involved in science, technology and engineering teachings at the Department of Chemical Engineering, Polytechnic School, Federal University of Bahia, Brazil. The author has a keen interest in subjects such as materials engineering, history of sciences and in particular, mathematics for laymen. 